\title{
Scoping review of implementing a longitudinal curriculum in undergraduate medical education: The wake forest experience
}

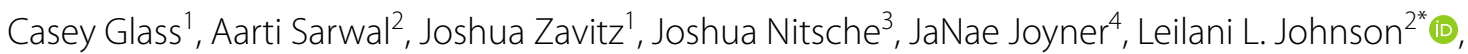 \\ Julia Garcia-Vargas ${ }^{2}$ and Mary Claire O'Brien ${ }^{1}$
}

\begin{abstract}
Background: Hands-on ultrasound experience has become a desirable component for undergraduate medical education (UGME) curricula throughout medical schools in the United States (US) to enhance readiness for future training. Ultrasound integration can be a useful assistive educational method in undergraduate medical education to improve anatomy and physiology skills. Relatively few medical schools have integrated ultrasound experiences formally into their 4-year medical school curriculum due to limitations of a resource intensive set up.

Methods: We undertook a scoping review of published UGME ultrasound curricula integrated into all four years in peer-reviewed as well online literature. In addition, we provide a narrative review of our institutional experience in conceptualization, design and implementation of UGME ultrasound curriculum driven by need to address the fading knowledge in anatomy and physiology concepts beyond pre-clinical years.

Results: Integrated ultrasound curriculum at WFSOM utilizes focused ultrasonography as a teaching aid for students to gain a more thorough understanding of basic and clinical science concepts taught in the medical school curriculum. We found 18 medical schools with ultrasound curricula published in peer-reviewed literature with a total of 33 ultrasound programs discovered by adding Google search and personal communication

Conclusions: The results of the review and our institutional experience can help inform future educators interested in developing similar curricula in their undergraduate programs. Common standards, milestones and standardized competency-based assessments would be helpful in more widespread application of ultrasound in UGME curricula.
\end{abstract}

Keywords: Medical education, Ultrasonography, Undergraduate medical education, Ultrasound, Curriculum

\section{Introduction}

The integration of hands-on ultrasound experience has become a highly desirable component for undergraduate medical education (UGME) curricula throughout the United States (US) as part of enhanced efforts to improve readiness of future doctors. Several schools have implemented a student-performed ultrasound experience to

\footnotetext{
*Correspondence: Iljohnso@wakehealth.edu

${ }^{2}$ Department of Neurology, Medical Center, Wake Forest School

of Medicine, 1 Winston-Salem, Boulevard, NC 27157, USA

Full list of author information is available at the end of the article
}

a variable degree throughout the formal 4-year medical school program and many individual medical specialties have incorporated ultrasound into their electives highlighting ultrasound based clinical applications [1, 2]. Programs have described the impact of ultrasound integration in medical education curriculum in helping enhance traditional learning of anatomy, medical physiology, and clinical skills of their medical students.

We investigated the published literature on curricular integration and its structure at a medical school level inform on factors to consider during UGME program development concerning ultrasound integration. 
We provide a scoping review of published curricular key metrics necessary for the development and implementation of UGME ultrasound program. We then describe our institutional experience in integrating ultrasound into the Wake Forest School of Medicine UGME curriculum emphasizing the challenges and lessons learned.

This synopsis on challenges, successes and impact in integrating ultrasound into UGME pre-clinical and clinical years can hopefully inform future UGME program development for schools exploring ways to improve their undergraduate programs.

\section{Methods}

1. A scoping review of literature was performed by authors (LJ, JGV, AS) using the electronic database PubMed, MEDLINE and the Cochrane Library in English literature using the following search words "Ultrasonography", Ultrasound", with the Boolean operators AND "Medical education", "Undergraduate", "School", "clerkship" AND "Curriculum" [2]. Two authors (LJ and JGV) independently manually reviewed titles and abstracts resulting in a list of specific articles that met the criteria of describing an UGME ultrasound curriculum program development. Search methods conform to the Preferred Reporting Items for Systematic Reviews and MetaAnalyses (PRISMA) guidelines for scoping reviews [3]. These were reviewed for full text to describe key features of each ultrasound curricula (LJ, JGV, AS). Since the emphasis of this review was to assess school of medicine supported curricula, articles were only included if they described the integrated ultrasound curriculum in relevance to UGME structure. Articles that restricted curriculum information to one specialty only were not included. This data was supplemented by open internet search through Google search engine for other curricula using the search words: "Ultrasonography", Ultrasound", with the Boolean operators AND "Medical education",
"Undergraduate", "School", "clerkship" AND "Curriculum". The results found were manually reviewed by authors (JGV and LJ) to look for publications that described full curricula. The first 10 pages of the Google results were manually reviewed to look for other published curricula. One of the authors (JGV) used survey-based questions via personal communication to complete the requisite information on unpublished ultrasound curricula to provide a comprehensive review of available programs (Table 1 and Appendix 1: Table 6). Questions were designed to address common components and themes in the curricula that were frequently discussed in published ultrasound curricula identified through literature review.

2. A narrative review of conceptualization, design, implementation and integration of ultrasound curriculum at WFSOM is presented emphasizing challenges and innovation. We describe the evolution of this curriculum based on framework provided by Kern [4].

\section{Results}

\section{Scoping review of ultrasound curricula in the US}

A scoping literature review of published ultrasound curricula was done to assess incorporation of ultrasound education in undergraduate medical education programs. This search yielded a total of 9,753 results. The review of titles and abstracts narrowed the results and full texts were reviewed by two independent authors (LJ and JGV). Design, implementation, and assessment of ultrasound education were described at 18 different institutions. Six additional records were included subsequently, four of these were personal references of senior authors and two were secondary references found on full text review of initial search (Fig. 1). A review of common data elements for these programs in presented in Table 2.

Table 1 Chronology of ultrasound curriculum development at wake forest school of medicine

\begin{tabular}{|c|c|c|c|}
\hline 2016 & 2017 & 2018 & 2019 \\
\hline $\begin{array}{l}\text { Introduction to Ultrasound } \\
\text { Cardiac Anatomy } \\
\text { Abdomen and Pelvis Anatomy } \\
\text { Neck Anatomy } \\
\text { Neurovascular Ultrasound } \\
\text { Cardiac Function } 1 \text { and } 2 \\
\text { Hepato-Biliary Ultrasound } \\
\text { Renal System Ultrasound }\end{array}$ & $\begin{array}{l}\text { Musculoskeletal Ultrasound } \\
\text { Endocrine Ultrasound } \\
\text { Ultrasound Guided Vascular Access } \\
\text { Ultrasound for Pregnancy } \\
\text { Point-of-Care Ultrasound elective }\end{array}$ & $\begin{array}{l}\text { Lung Ultrasound } \\
\text { Point-of-Care Echocardiography } \\
\text { Dedicated teaching sonographer added to } \\
\text { curriculum }\end{array}$ & $\begin{array}{l}\text { Ultrasound certificate program } \\
\text { Ultrasound simulator }\end{array}$ \\
\hline
\end{tabular}




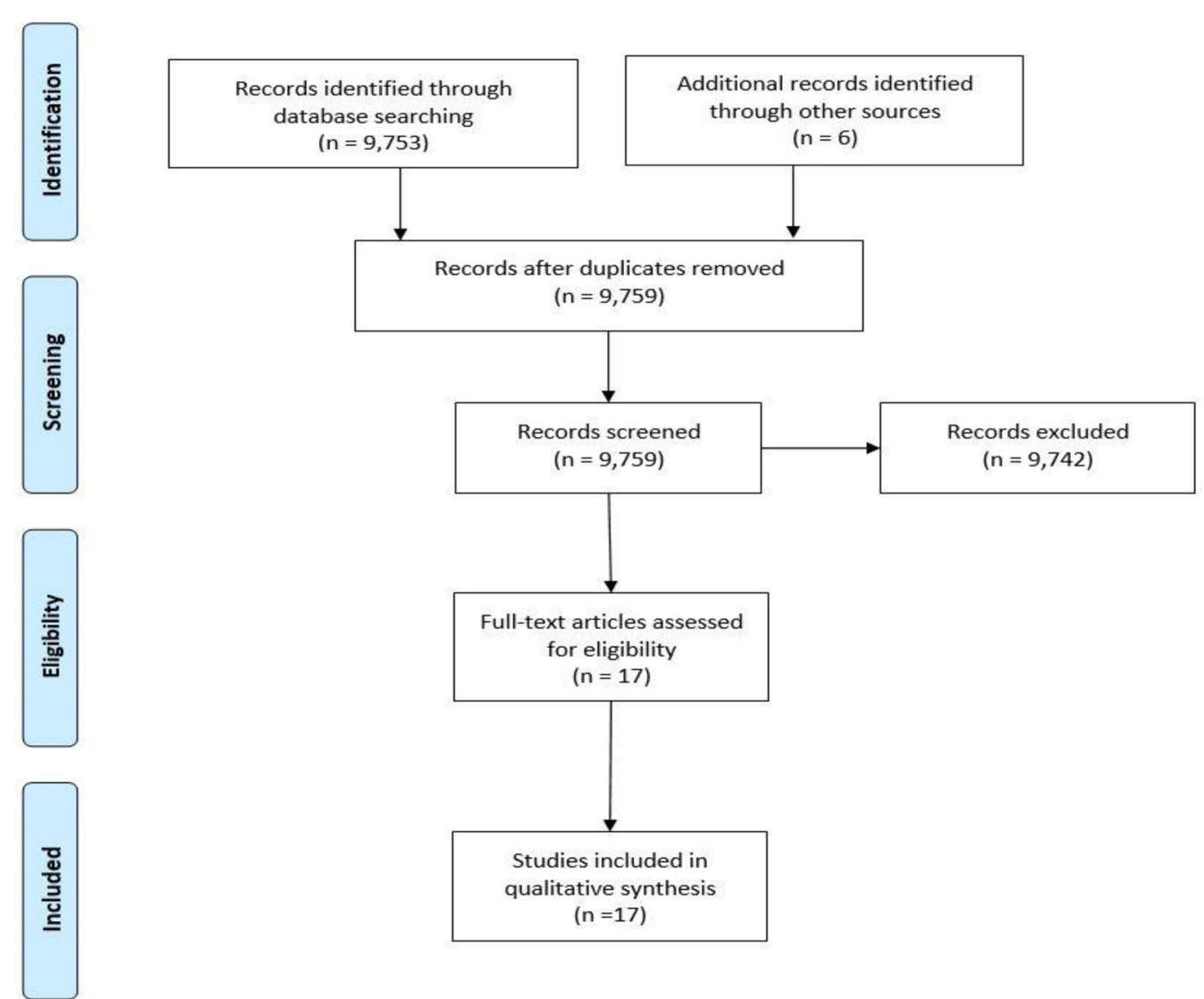

Fig. 1 PRISMA diagram showing scoping review employed by authors

\section{Duration/curricular structure}

Most schools incorporated ultrasound into 1-2 years of UGME but few describe a vertical four-year medical school ultrasound curriculum $[1,5,8,9,12-14]$. A majority of undergraduate medical school programs incorporated ultrasound instruction in the pre-clinical years by offering it concurrently with gross anatomy, physical examination, or clinical skills courses or integrating it into similar existing courses in the form of modules. The spectrum of curricular structure was broad at each institution ranging from vertical, organ-systems based, and staged curricula. Consistent training and practice during the clinical years was uncommon. When schools did offer electives or "selectives" in ultrasound, ultrasound education was targeted to a specific specialty that has significant clinical integration of ultrasound (e.g., radiology, obstetrics, emergency ultrasound, etc.) and available to all third- or fourth- year students interested in that specialty.

\section{Mode of integration}

The mode of integration at institutions varied from: concurrently with anatomy, basic science lectures, and clinical courses; expanded medical program of study; problem-based learning; clinical skills; incorporated into second year practical sessions; integrated into new clinical ultrasound elective, principles of clinical courses, clinical rotations, and specialty electives; and even ran parallel to clerkships.

\section{Instructional formats}

The format of information delivery across the various programs varied greatly: hands-on sessions, open-access podcast lectures, didactics, web-based learning modules, video assignments, workshops, scanning demonstrations, large and small group sessions, clinical learning through cases, field hospital visit, and independent scanning. A universal characteristic of almost all these programs was delivery of instructional material in a multimodal format, usually as a combination of the methods listed above. Other shared components included the use of the "flipped classroom" instructional method and formal introductory modules for ultrasound imaging and application. 


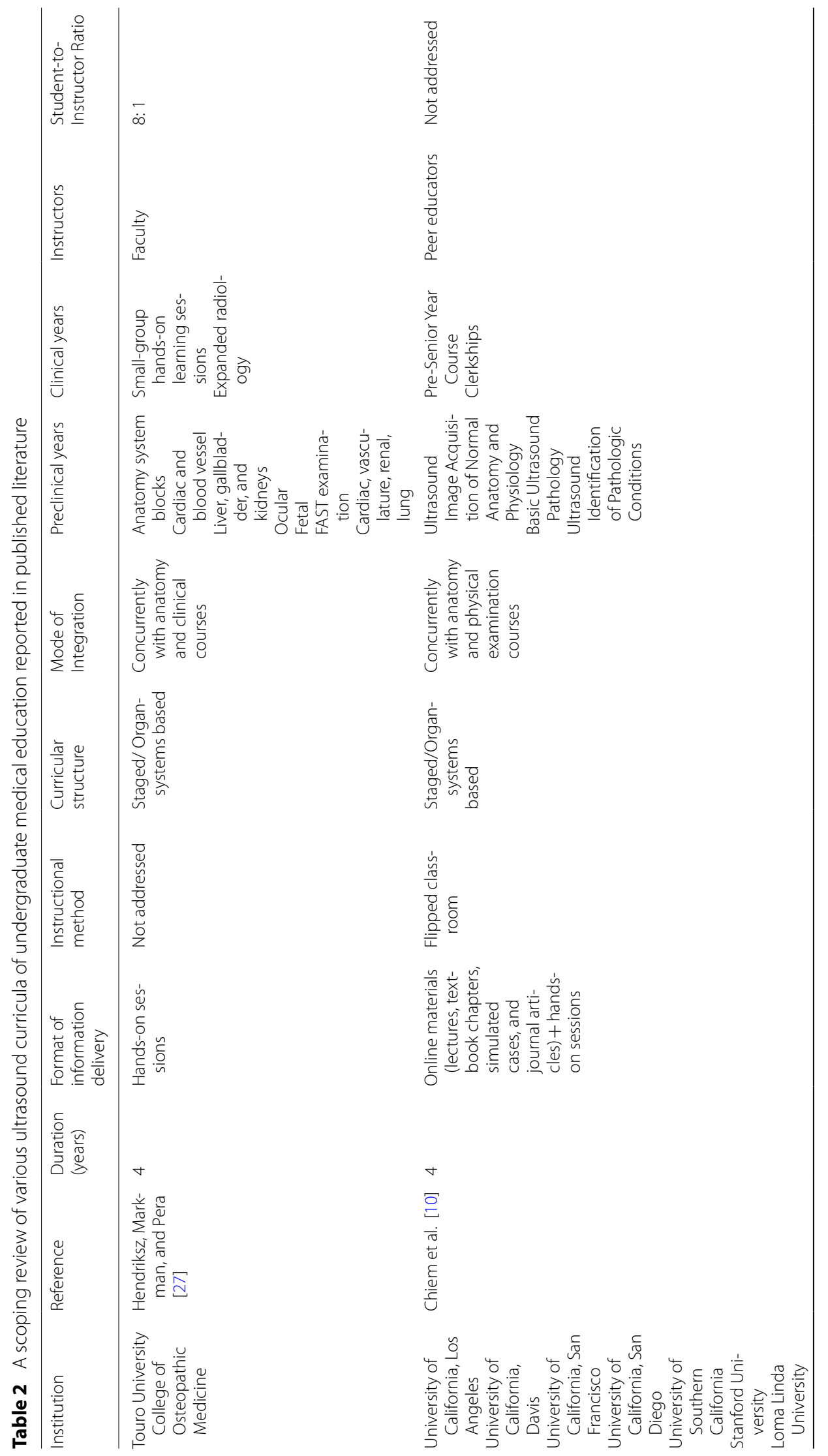


Glass et al. Ultrasound J $\quad$ (2021) 13:23

Page 5 of 21

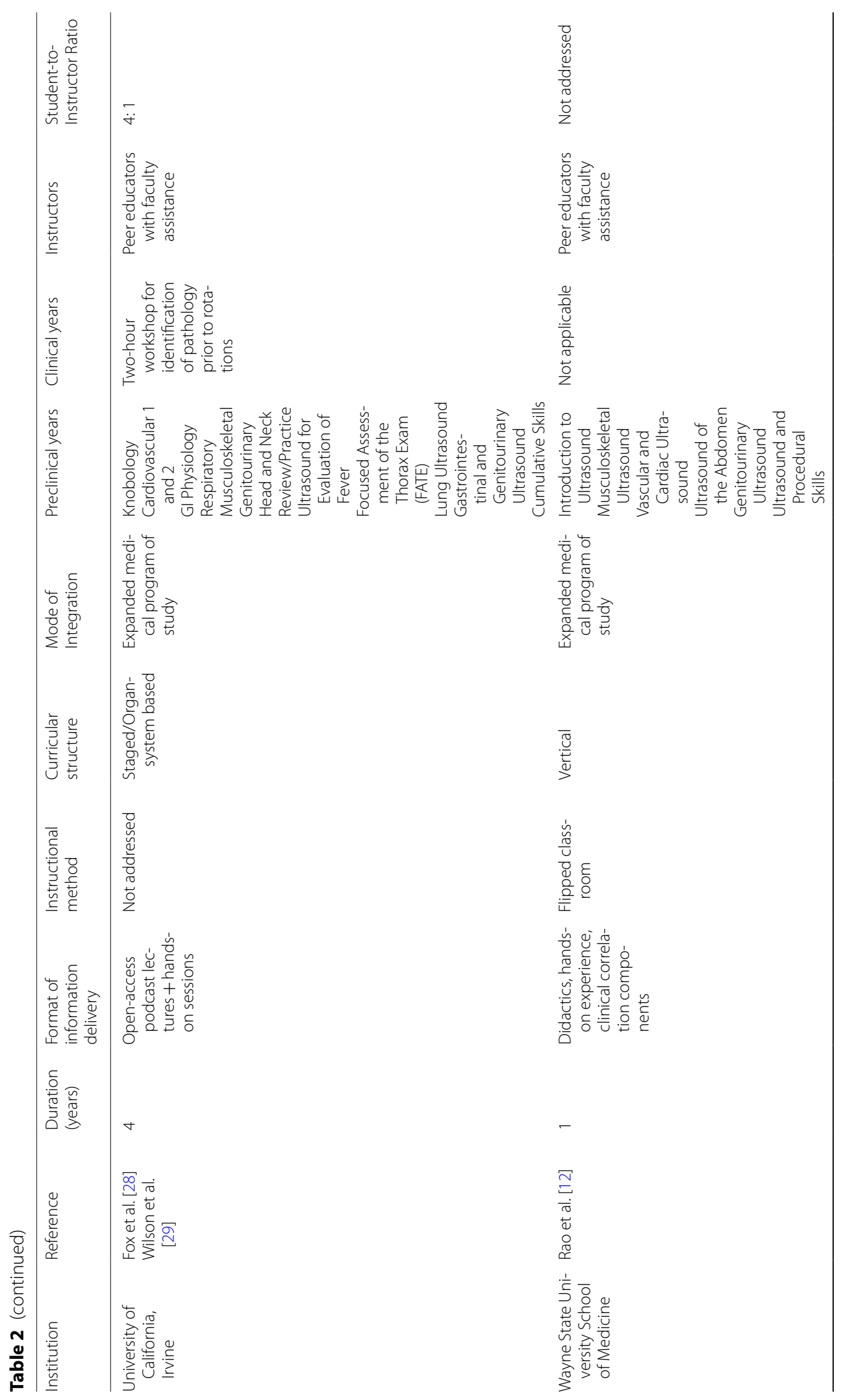




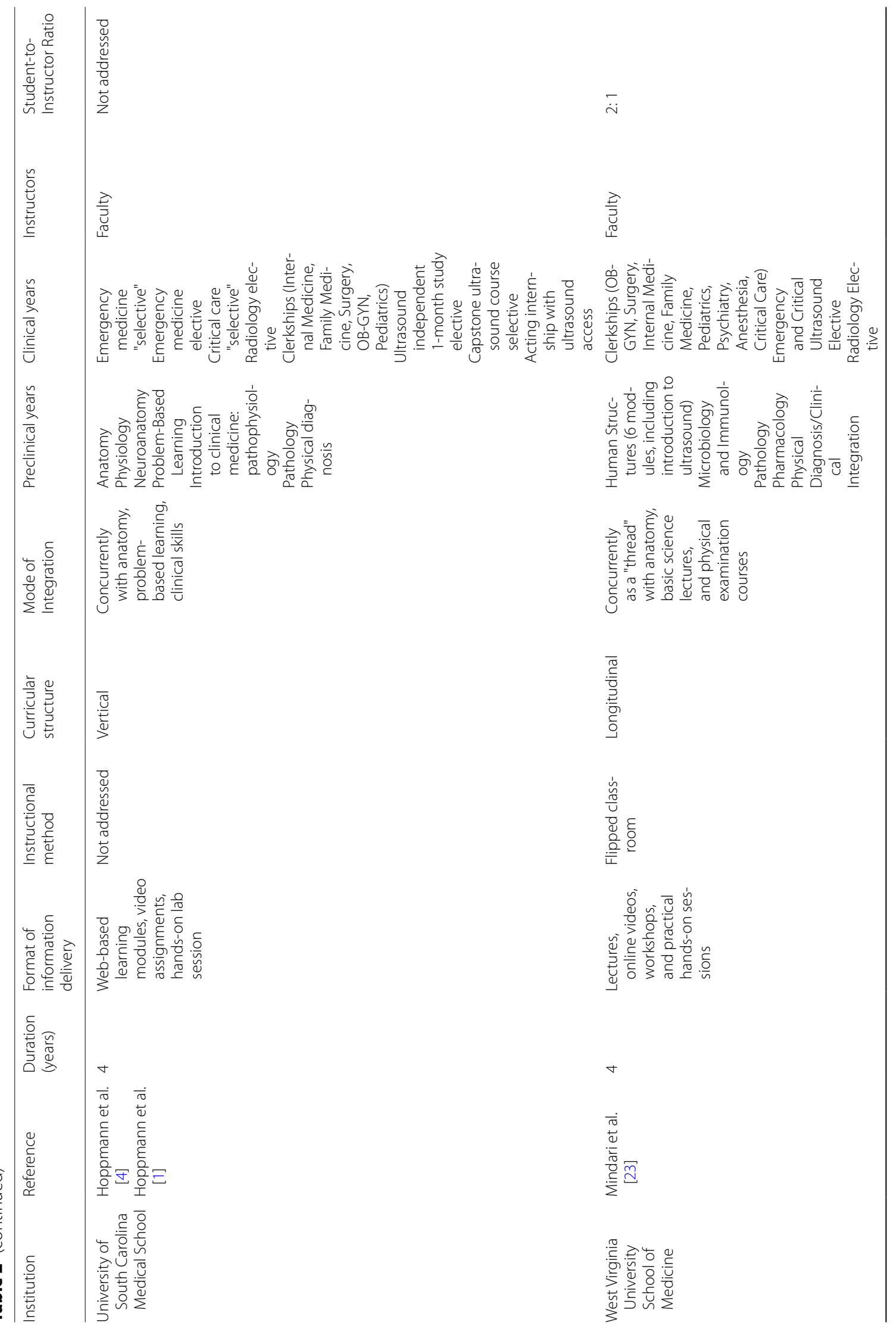




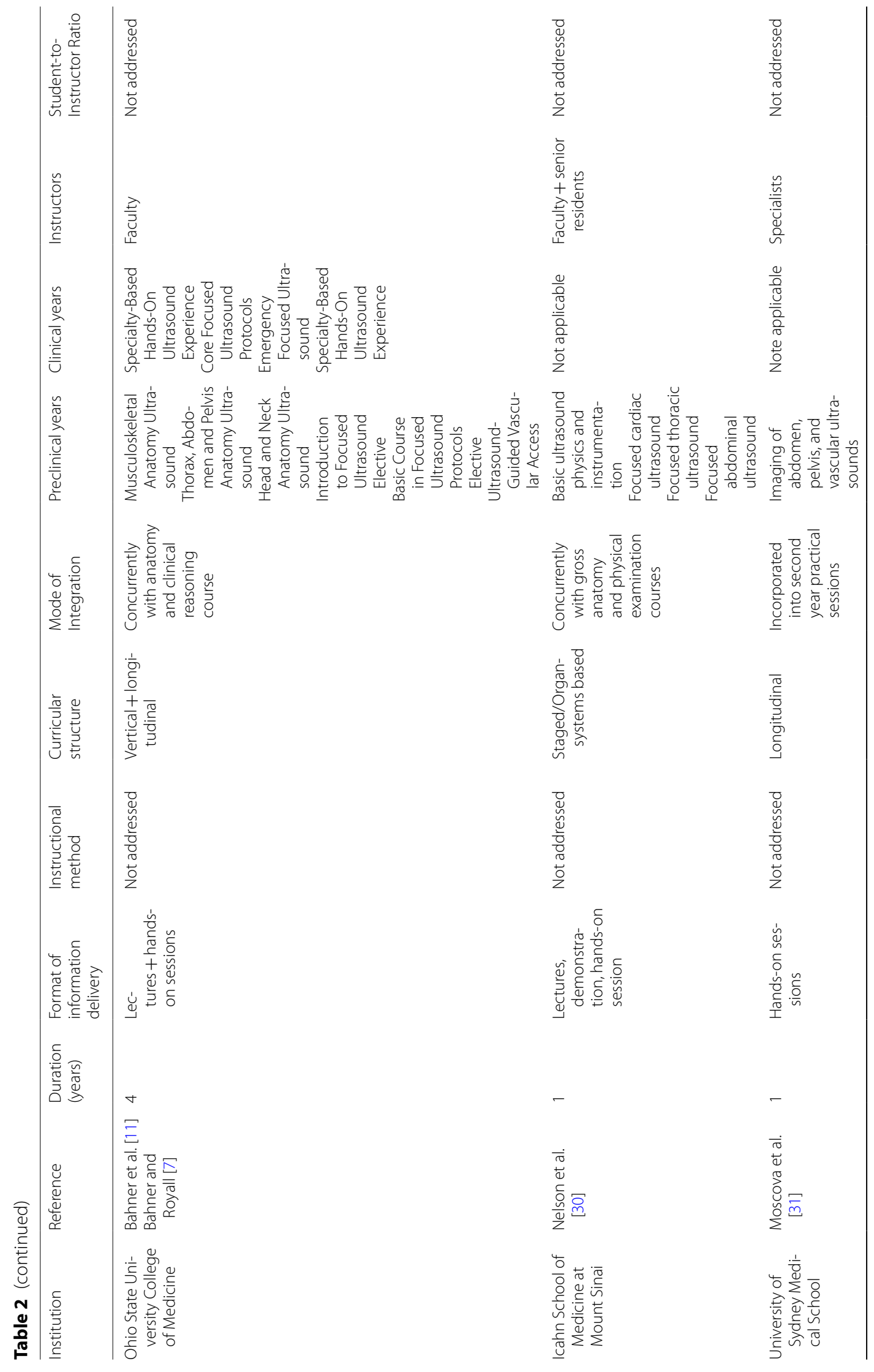




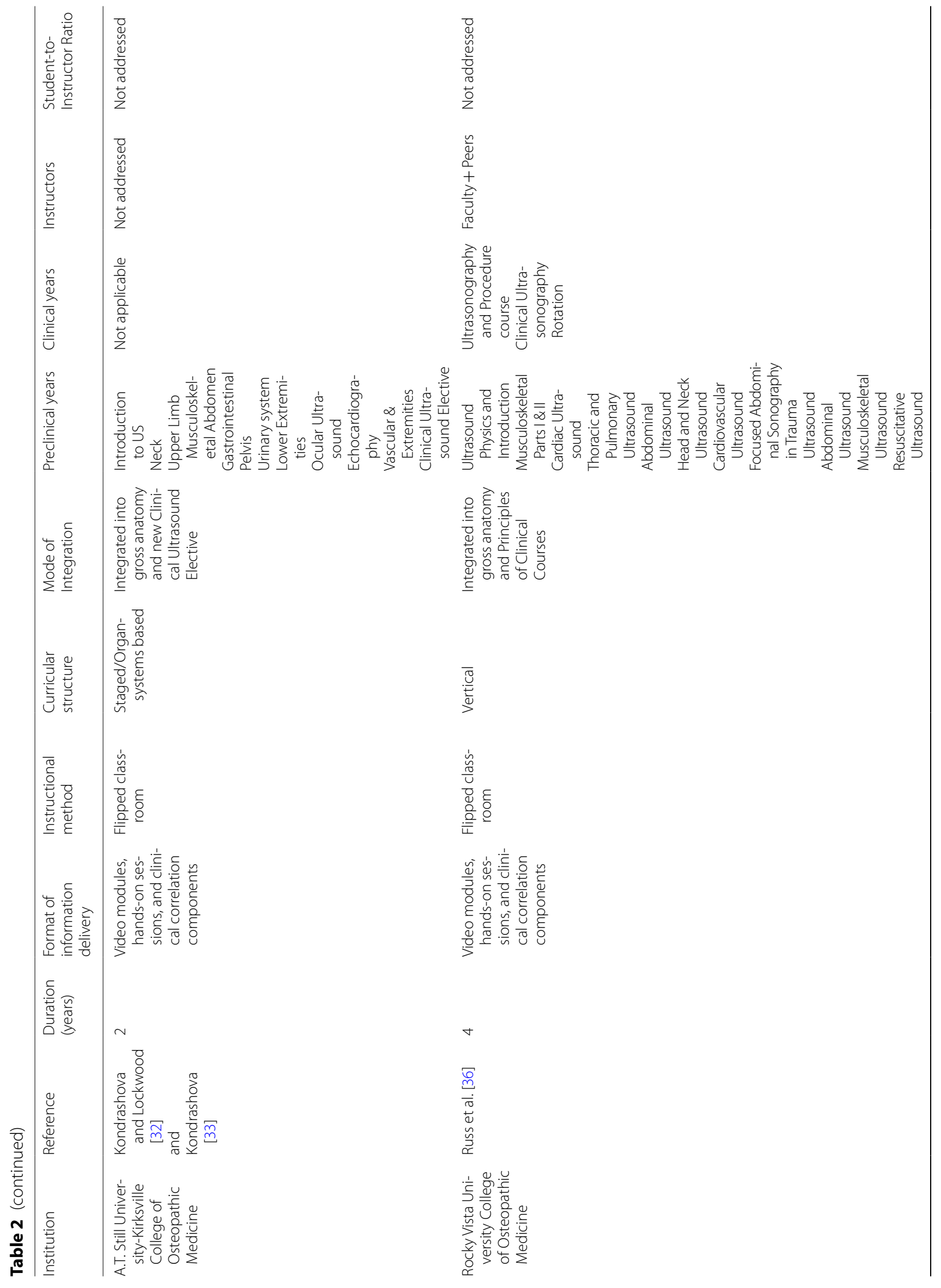




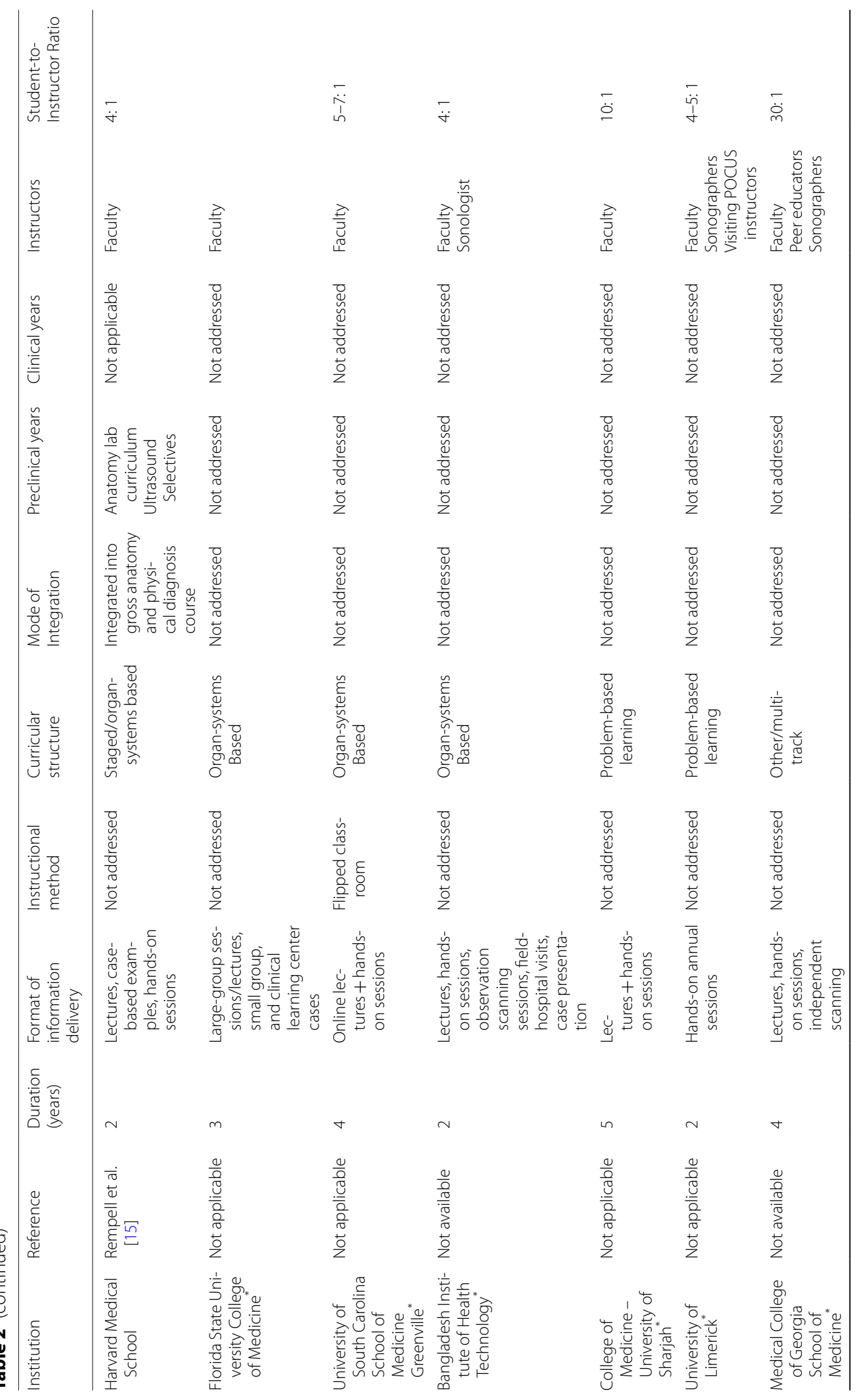




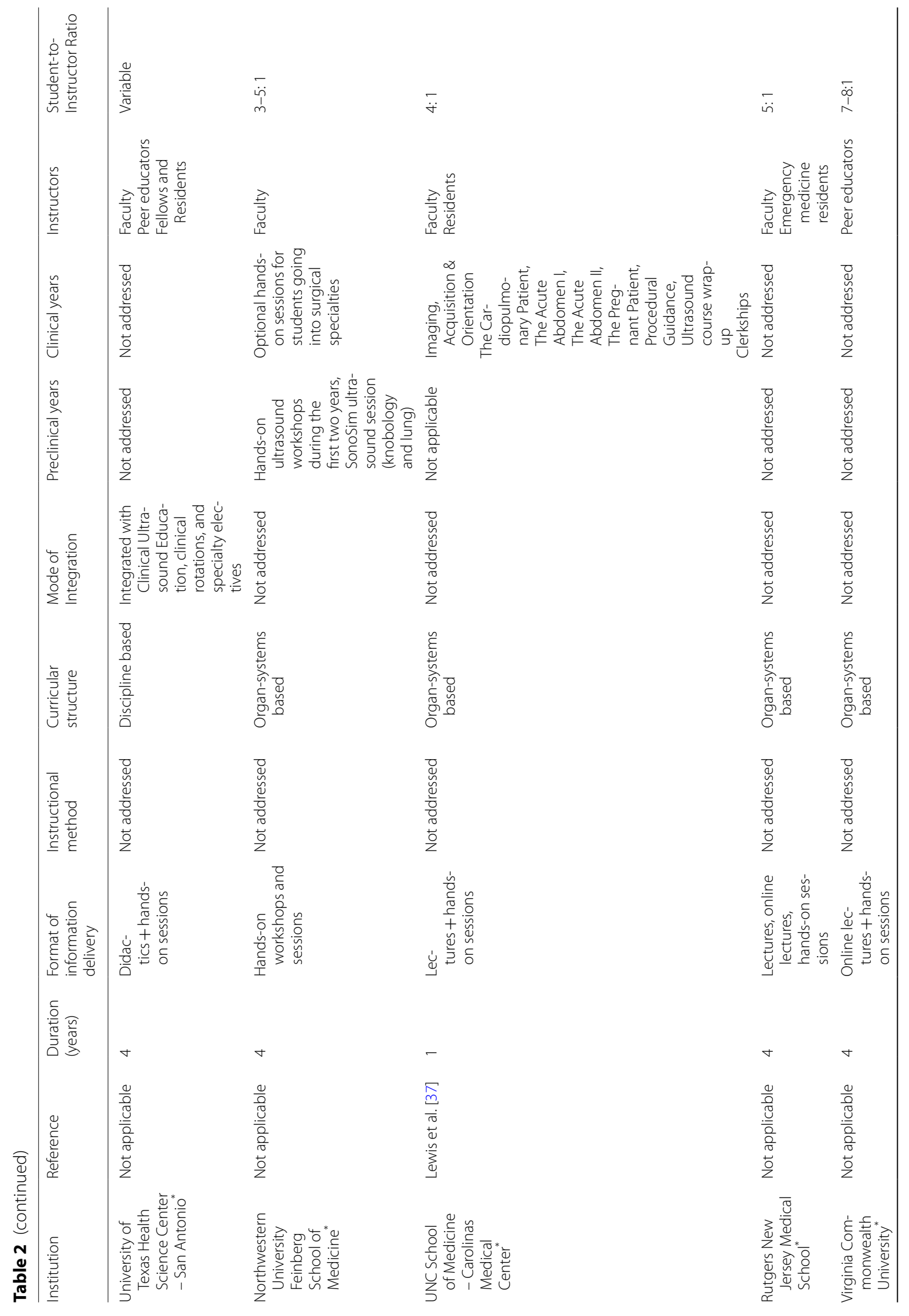




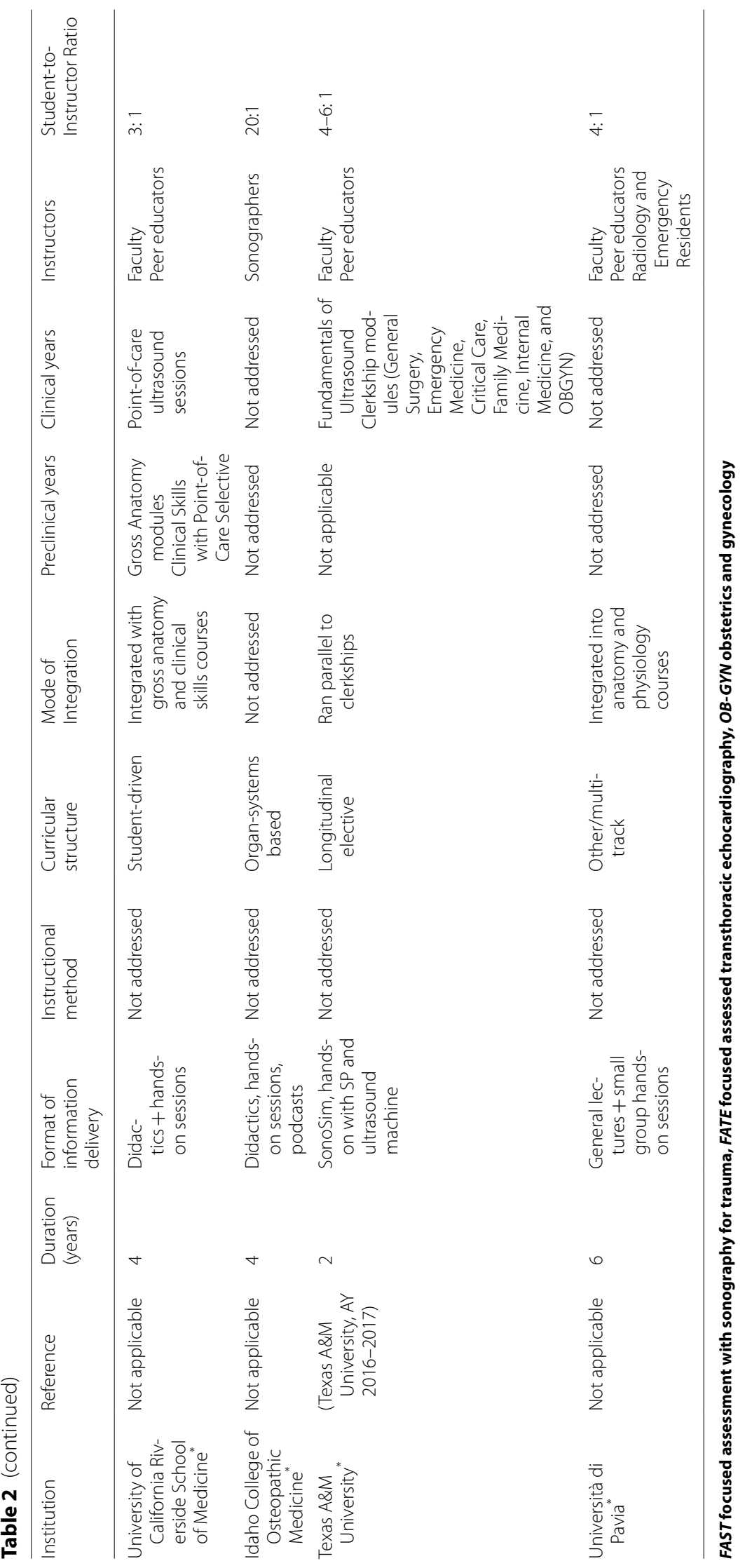




\section{Instructors}

Programs described varied instructors recruited to teach: faculty, sonographers, specialty-specific residents, and visiting POCUS instructors or specialists. A few ultrasound programs utilized peer educators as the primary instructors for hands-on ultrasound imaging sessions, the rest depended on ultrasound-trained faculty or house-staff with some programs using trained sonographers [8, 15-17]. A few programs included instructortraining sessions to standardize teaching. The student to instructor ratio ranged from 1:2 to 1:30.

\section{Evaluation of program}

General consensus supports that ultrasound instruction at the UGME level can facilitate efficient patient care and provide a basis for advanced ultrasound training in graduate and continuing medical education [10]. Only a handful of schools reported the impact of ultrasound education UGME in measurable formats like enhanced performance on standardized tests, enhanced physical exam skills by providing real time visual feedback on examination finding, improving the diagnostic accuracy of pathological exam findings, enhancing critical thinking skills by providing real time information corroborating or refuting differential diagnosis [5, 18-21]. One school conducted a retrospective analysis of the Comprehensive Osteopathic Medical Licensing Examination of the United States (COMLEX-USA) level 1 scores in anatomy, diagnostic technology, and osteopathic principals and practice. Scores markedly increased across all three areas from twenty or more below the national mean to up to twenty-eight points above the national mean over three years attributable to ultrasound integration.

\section{Integrated ultrasound curriculum development at wake forest school of medicine} Curricular structure prior to implementation of ultrasound curriculum

Like most Liaison Committee on Medical Education (LCME) accredited programs, Wake Forest institutional curriculum for UGME Doctor of Medicine (MD) students consists of 18 months of pre-clinical courses in human anatomy, histology, bioethics, population health, and systems-based pathophysiology in a variety of instructional formats including lectures, laboratory experiences, small group exercises, case-based learning, and asynchronous education. Students transition to clinical rotations in February of their second academic year and begin senior acting internship and elective experiences in March of their third academic year. Major components of the curriculum are delivered in a block format where topics follow each other through the calendar year (Fig. 2). The MD UGME program includes non-block format "threads" which are taught, to 150 students per year, in tandem with other curricular elements throughout all 4 years. Examples at our institution include pharmacology, bioethics, population health, physical exam and diagnosis (Tables 3 and 4). Threads are taught in parallel to the underlying block schedule to emphasize the thread content most relevant to the current pathophysiology block. We describe the evolution of this curriculum based on the 6-step framework provided by Kern for curricular development in medical education [4].

a. Problem identification and general needs assessment: An institutional needs analysis demonstrated fading command of anatomy and physiology concepts after the pre-clinical years that was not being addressed with current curricular structure. In exploring solutions, the Departments of Emergency Medicine and Neurology were found to have existing educational models integrating ultrasound as a visual and interactive tool to reinforce clinical concepts with access to ultrasound machines and ultrasound-trained faculty.

b. Targeted needs assessment: After prioritizing the need to develop an integrated ultrasound curriculum, an approach of problem-centered curriculum design was chosen and a team of faculty with content expertise was created. Town hall and in-person meetings with UGME course directors and clinical leaders were held to identify the content that would gain the most from hands-on ultrasound experiences to target synergy between ultrasound laboratory exercises and the objectives of the general medical student curriculum.

c. Goals and objectives: Frequency and duration of these ultrasound didactic modules and labs was designed to focus on the use of ultrasound as a "clinical tool" to teach pre-clinical students anatomy in Year 1 and physiology in Year 2 with minimum course scheduling changes in existing structure.

d. Educational strategies and evaluation/feedback: Above efforts led to integration of hands-on ultrasound as one of these longitudinal threads in UGME in 2014 to provide an enhanced learning experience for medical students. For each component of the curriculum, the pedagogy that seemed most promising to address the problem of fading basic science concepts among students and application in clinical years and is described below specific to each year.

i. Year 1 and 2 preclinical curriculum: The curriculum was conceptualized in a "flipped classroom" model to include didactic instruction 
through online modules followed by laboratory component with hands-on ultrasound training labs with greater emphasis on experiential learning (Tables 3 and 4) [6]. Online modules were recorded with easily available software (QuickTime, Apple, Inc., 1991) as 20-60 min online screencast lectures posted on the medical school learning management system (Canvas, Instructure, 2011). Didactic content emphasizes recognition of normal anatomic relationships between organs and tissues using ultrasound cine loops with information on ultrasound scanning technique, image interpretations and clinical applications. Student assessment is performed via formative pretests and summative post-testing questions. Ultrasound hands-on lab sessions occur over 4-h blocks. The 1-h session is repeated hourly for a quarter of the class (30-40 students) per session. Students are divided into groups of 4-5 students per machine and facilitated by one to four faculty members per session. Lab sessions move methodically through a series of imaging objectives focusing on scanning techniques and anatomy identification. The remaining students not participating in ultrasound lab are often in other parallel class activities such as anatomy dissection or small group sessions.

Student assessment is performed via formative pre-tests and summative post-testing questions that are course specific quizzes. We also incorporated ultrasound related content on core curricular exams. Lab participation is mandatory and forms a component of the course grade. For each module, students complete a formative pre-test quiz assessing their general ultrasound knowledge and content specific anatomic knowledge before reviewing the online lecture that is followed by another summative quiz testing their grasp on image interpretation in relation to anatomy, physiology and clinical concepts.

ii. Year 3 clinical curriculum: Increasing popularity and positive feedback from medical students participating in the curriculum resulted in extending the ultrasound component to the UGME clinical clerkship year in 2016. The didactic and lab sessions follow the similar flipped classroom model with content focused on clinical concepts corresponding to the clinical clerkship. After an online review of lectures reorienting students to relevant ultrasound anatomy and physiology, one-hour sessions are organized by physicians during the clinical clerkships under the guidance of the ultrasound curriculum leadership (Table 4). The sessions are designed to focus on structured bedside exams commonly used by providers in the patient care environment. In rotations like obstetrics, ultrasound was focused on pregnancy and fetal pig phantoms were used to highlight clinical concepts [7]. Following formal didactic and laboratory sessions, students are encouraged to participate in bedside ultrasound exams as opportunities arise during their clinical clerkship.

iii. Year 4 clinical curriculum: The final year of ultrasound curriculum for year 4 was added in 2017 as a POCUS elective unique to a handful of programs [8]. This multidisciplinary elective was initially offered to 1 student per block and now accommodates 2 students every block and taught 22 students in its third year. The focus of this 4-week elective is hands-on experience designed to improve bedside image acquisition and skills in point-of-care examinations. Student rotate in emergency and critical care settings in the first two weeks and subspecialty experiences in the final two weeks to increase the awareness of clinical applications of ultrasound in diagnostic and point-of-care use across various subspecialties. Elective rotation settings include: Emergency Medicine, Neurology, Medical-Critical Care, Neurocritical Care, Cardiology, Obstetrics and Gynecology (OB/GYN), Trauma Surgery, Vascular Surgery, Pediatric Cardiology, Internal Medicine, Community Medicine, and Sports Medicine. Students maintain a digital portfolio of at least 25 scans during this rotation [9]. The POCUS elective is a very distinctive and popular component of Wake Forest's UGME curriculum due to its multidisciplinary format packaged within one block translating bedside imaging into clinical concepts across a wide range of specialties. Assessment for the 4th year elective occurs through direct observation of scanning and clinical application concepts, review of case logs, online quizzes, a mandatory student led presentation or review of ultrasound- 


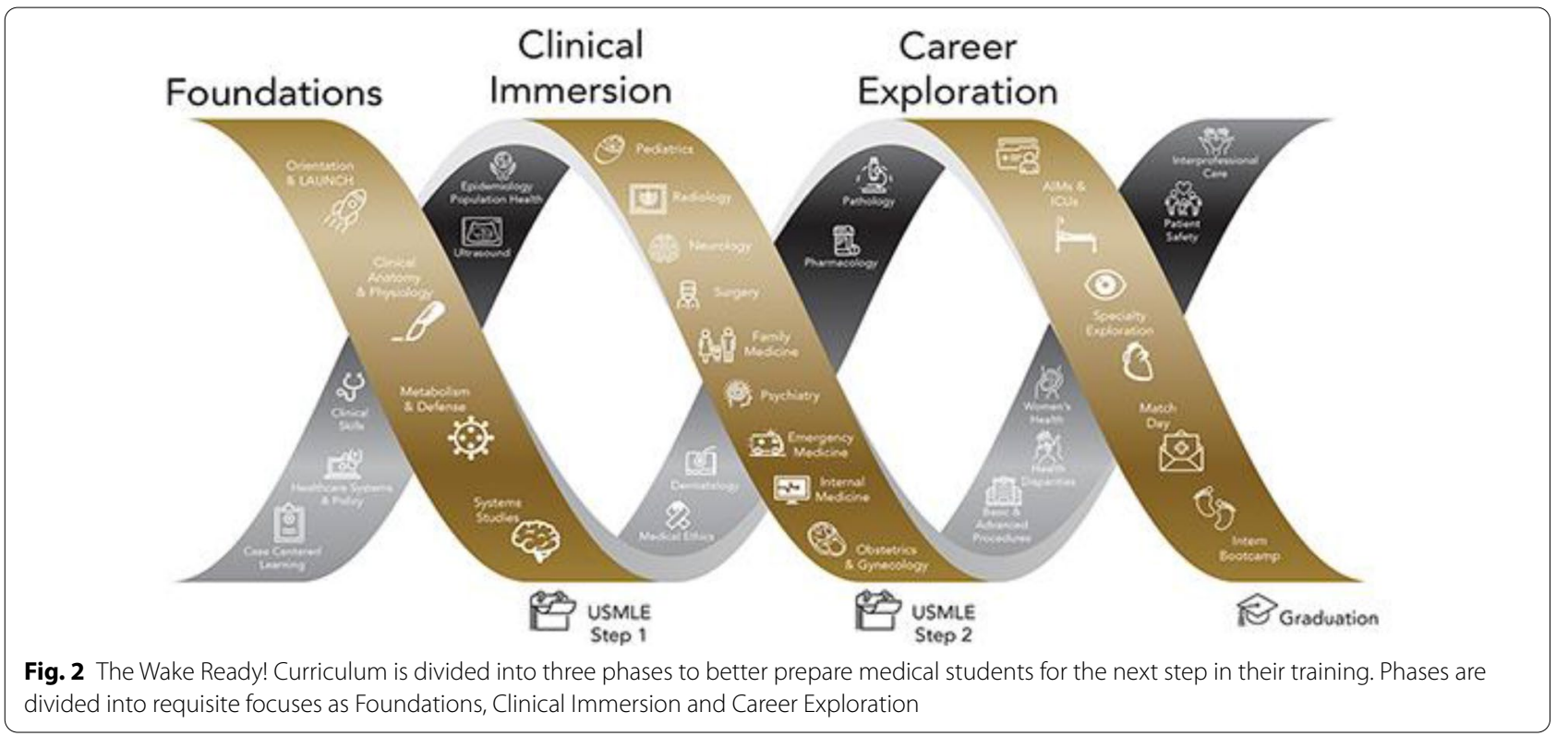

related research article on an ultrasound topic of their choice.

\section{Implementation}

A private philanthropic grant awarded by The Fullerton Foundation in 2014 totaling $\$ 300,000$ was secured to fund this new model for 3 years. The grant was earmarked for faculty effort to design curriculum; collaboration effort from University of South Carolina faculty as we developed curriculum; program staff support; travel to conferences; and capital equipment including 4 machines and consumable supplies. Matching institutional funds provided seed money for faculty release time to develop education modules and deliver hands-on sessions for medical students. Because the University of South Carolina School of Medicine-Greenville (USC-G) was one of the first institutions with an integrated curriculum, we sought out a collaboration with faculty at USC-G to ensure a streamlined launch of our UGME curriculum $[1,3]$. Loaned equipment from the Center for Medical Ultrasound and Department of Emergency Medicine supplemented the machines purchased from seed grant. Program infrastructure detail are described in Table 5.

In all lab sessions through pre-clinical and clinical year, students volunteer as ultrasound models for each other and perform ultrasound imaging of relevant anatomic structures for each module over their assigned lab. Participation as an ultrasound model is voluntary with a high rate of participation and yearly electronic acknowledgment of the Student Model Policy and Policy for Management of Incidental Findings (Fig. 3). Students with incidental findings are referred to our student health system with initial direct communication between the ultrasound course director, the student, and the director of student health. To date, an annual average of 5 of 360 students over 31 hours of labs scanning have been referred for additional evaluation of incidental findings. Laboratory sessions associated with an increased risk of referral include Neck and Endocrine Laboratory sessions (2 students with thyroid nodules or mass) and Abdomen/ Renal sessions (2 students with unilateral renal agenesis, one student with splenic lesion).

\section{Discussion}

The last 10 years have seen UGME instruction in handson ultrasound skills go from niche to mainstream. Institutions opt to integrate ultrasound education into their medical school curriculum primarily because ultrasonography offers the potential to be an efficient educational tool that enhances traditional learning of anatomy, medical physiology, and clinical skills $[5,8,14,16]$. Published programs have demonstrated the feasibility of integrating a POCUS curriculum into UGME and emerging data suggests that students perceive value in this effort. Focused ultrasonography can be used as a useful aid in teaching anatomy to medical students, learning physical exam skills; and has been received quite positively by medical students at several institutions $[8,21]$. A national survey of 82 medical schools, where 51 report some ultrasound integration into UGME, found that $>90 \%$ of students preferred ultrasound incorporated into their program, $>80 \%$ 
Table 3 First and second year medical student ultrasound curriculum as part of a longitudinal program at wake forest

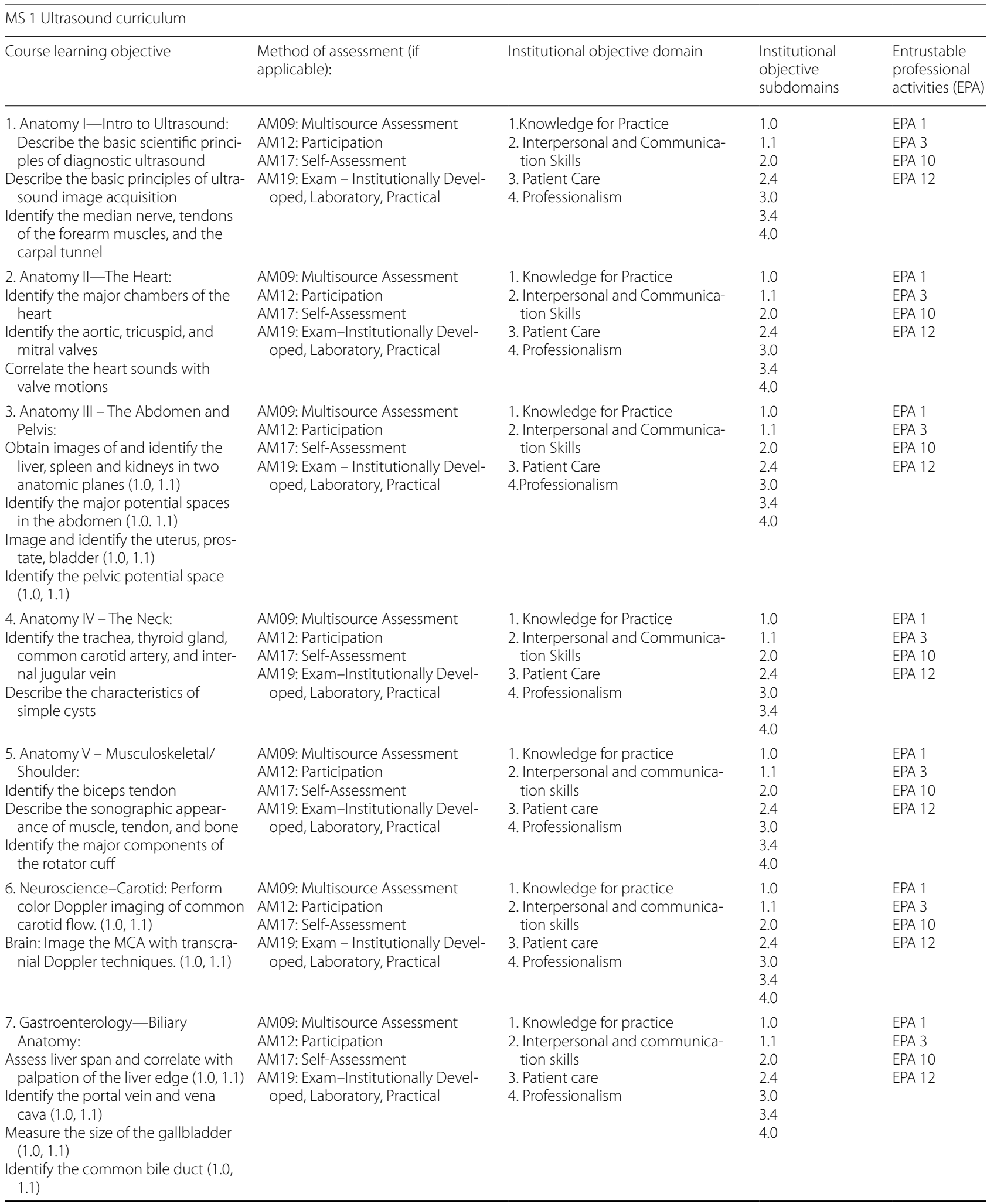


Table 3 (continued)

\begin{tabular}{|c|c|c|c|c|}
\hline \multicolumn{5}{|l|}{ MS 1 Ultrasound curriculum } \\
\hline Course learning objective & $\begin{array}{l}\text { Method of assessment (if } \\
\text { applicable): }\end{array}$ & Institutional objective domain & $\begin{array}{l}\text { Institutional } \\
\text { objective } \\
\text { subdomains }\end{array}$ & $\begin{array}{l}\text { Entrustable } \\
\text { professional } \\
\text { activities (EPA) }\end{array}$ \\
\hline $\begin{array}{l}\text { 8. Pulmonology - Lung: } \\
\text { Assess lung slide }(1.0,1.1) \\
\text { Assess diaphragm - excursion (1.0, } \\
\text { 1.1) } \\
\text { Identify diaphragm in ultrasound } \\
\text { image }(1.0,1.1)\end{array}$ & $\begin{array}{l}\text { AM09: Multisource Assessment } \\
\text { AM12: Participation } \\
\text { AM17: Self-Assessment } \\
\text { AM19: Exam-Institutionally Devel- } \\
\text { oped, Laboratory, Practical }\end{array}$ & $\begin{array}{l}\text { 1. Knowledge for Practice } \\
\text { 2. Interpersonal and communica- } \\
\text { tion skills } \\
\text { 3. Patient care } \\
\text { 4. Professionalism }\end{array}$ & $\begin{array}{l}1.0 \\
1.1 \\
2.0 \\
2.4 \\
3.0 \\
3.4 \\
4.0\end{array}$ & $\begin{array}{l}\text { EPA } 1 \\
\text { EPA } 3 \\
\text { EPA } 10 \\
\text { EPA } 12\end{array}$ \\
\hline $\begin{array}{l}\text { 9. Cardiopulmonary - The Heart I } \\
\text { Identify and Assess mitral valve } \\
\text { motion }(1.0,1.1) \\
\text { Identify diastole and systole on } \\
\text { echocardiographic images (1.0, } \\
\text { 1.1) } \\
\text { Associate heart sounds with cardiac } \\
\text { motion }(1.0,1.1)\end{array}$ & $\begin{array}{l}\text { AM09: Multisource Assessment } \\
\text { AM12: Participation } \\
\text { AM17: Self-Assessment } \\
\text { AM19: Exam - Institutionally Devel- } \\
\text { oped, Laboratory, Practical }\end{array}$ & $\begin{array}{l}\text { 1. Knowledge for practice } \\
\text { 2. Interpersonal and communica- } \\
\text { tion skills } \\
\text { 3. Patient care } \\
\text { 4. Professionalism }\end{array}$ & $\begin{array}{l}1.0 \\
1.1 \\
2.0 \\
2.4 \\
3.0 \\
3.4 \\
4.0\end{array}$ & $\begin{array}{l}\text { EPA } 1 \\
\text { EPA } 3 \\
\text { EPA } 10 \\
\text { EPA } 12\end{array}$ \\
\hline $\begin{array}{l}\text { 10. Cardiopulmonary - Cardiac } \\
\text { Functional Assessment: } \\
\text { Measure the E-point septal separa- } \\
\text { tion }(1.0,1.1) \\
\text { Measure the ejection fraction in the } \\
\text { LV } 2 \text { chamber view and the Apical } \\
4 \text { chamber view }(1.0,1.1)\end{array}$ & $\begin{array}{l}\text { AM09: Multisource Assessment } \\
\text { AM12: Participation } \\
\text { AM17: Self-Assessment } \\
\text { AM19: Exam - Institutionally Devel- } \\
\text { oped, Laboratory, Practical }\end{array}$ & $\begin{array}{l}\text { 1. Knowledge for practice } \\
\text { 2. Interpersonal and communica- } \\
\text { tion skills } \\
\text { 3. Patient care } \\
\text { 4. Professionalism }\end{array}$ & $\begin{array}{l}1.0 \\
1.1 \\
2.0 \\
2.4 \\
3.0 \\
3.4 \\
4.0\end{array}$ & $\begin{array}{l}\text { EPA } 1 \\
\text { EPA } 3 \\
\text { EPA } 10 \\
\text { EPA } 12\end{array}$ \\
\hline $\begin{array}{l}\text { 11. Renal - The urinary tract: } \\
\text { Identify the right and left kidneys } \\
(1.0,1.1) \\
\text { Measure the size of a kidney }(1.0,1.1) \\
\text { Measure the volume of the bladder } \\
(1.0,1.1) \\
\text { Identify ureteral jets in the bladder } \\
(1.0,1.1)\end{array}$ & $\begin{array}{l}\text { AM09: Multisource Assessment } \\
\text { AM12: Participation } \\
\text { AM17: Self-Assessment } \\
\text { AM19: Exam - Institutionally Devel- } \\
\text { oped, Laboratory, Practical }\end{array}$ & $\begin{array}{l}\text { 1. Knowledge for practice } \\
\text { 2. Interpersonal and communica- } \\
\text { tion skills } \\
\text { 3. Patient care } \\
\text { 4. Professionalism }\end{array}$ & $\begin{array}{l}1.0 \\
1.1 \\
2.0 \\
2.4 \\
3.0 \\
3.4 \\
4.0\end{array}$ & $\begin{array}{l}\text { EPA } 1 \\
\text { EPA } 3 \\
\text { EPA } 10 \\
\text { EPA } 12\end{array}$ \\
\hline $\begin{array}{l}\text { 12. Endo-Thyroid: } \\
\text { Identify the thyroid gland }(1.0,1.1) \\
\text { Identify the trachea }(1.0,1.1) \\
\text { Measure the volume of the thyroid } \\
\text { gland }(1.0,1.1)\end{array}$ & $\begin{array}{l}\text { AM09: multisource assessment } \\
\text { AM12: Participation } \\
\text { AM17: Self-Assessment } \\
\text { AM19: Exam - Institutionally Devel- } \\
\text { oped, Laboratory, Practical }\end{array}$ & $\begin{array}{l}\text { 1. Knowledge for Practice } \\
\text { 2. Interpersonal and communica- } \\
\text { tion skills } \\
\text { 3. Patient care } \\
\text { 4. Professionalism }\end{array}$ & $\begin{array}{l}1.0 \\
1.1 \\
2.0 \\
2.4 \\
3.0 \\
3.4 \\
4.0\end{array}$ & $\begin{array}{l}\text { EPA } 1 \\
\text { EPA } 3 \\
\text { EPA10 } \\
\text { EPA } 13\end{array}$ \\
\hline
\end{tabular}

MS1 first year medical student, EPA entrustable professional activities, MCA middle cerebral artery, LV left ventricular

felt that ultrasound sessions enhanced training in both pre-clinical and clinical courses, and $60-90 \%$ students reported increased confidence in physical exam skills after visualizing anatomy by ultrasound $[1,5,11,14,21]$. In 2014 , fewer than $60 \%$ of medical schools reported some level of ultrasound training in UGME; and almost $80 \%$ agreed that it should be included in UGME but fewer than 20\% prioritized it [22]. The American Institute of Ultrasound in Medicine hosts a self-reported list of all medical schools with UGME ultrasound curricula and reports 66 of 222 LCME accredited schools have some level of structured ultrasound instruction. Only 25 list a 4 -year ultrasound curriculum $[1,5,8,12,23,24]$. Though national consensus curricula have been published by several organizations, lack of guidelines or LCME inclusion of ultrasound similar to the Accreditation Council for Graduate Medical Education (ACGME) endorsement for emergency medicine residency is a barrier towards widespread POCUS UGME programs [25-27]. 
Table 4 Third year medical student ultrasound curriculum as part of a longitudinal program at wake forest

\begin{tabular}{|c|c|c|}
\hline Exam & Rotation & Learning Objectives \\
\hline Bedside echo & Internal medicine & $\begin{array}{l}\text { 1. Describe indications for a bedside echocardiogram } \\
\text { 2. Describe ultrasound findings related to intravascular volume status } \\
\text { 3. Describe the sonographic characteristics of tamponade on } 2 D \text { imaging } \\
\text { 4. Describe ultrasound findings related to systolic dysfunction } \\
\text { 5. Demonstrate the standard echocardiographic views for the exam }\end{array}$ \\
\hline $\begin{array}{l}\text { Focused assessment with sonogra- } \\
\text { phy in trauma }\end{array}$ & Surgery & $\begin{array}{l}\text { 1. Describe indications for a FAST exam } \\
\text { 2. Describe implications for downstream patient care based on exam findings } \\
\text { 3. Describe the appearance of abdominal free fluid in each sonographic } \\
\text { window } \\
\text { 4. Describe the sonographic characteristics of tamponade on } 2 D \text { imaging } \\
\text { 5. Demonstrate the standard ultrasound views for the exam }\end{array}$ \\
\hline Ultrasound in pregnancy & Obstetrics and gynecology & $\begin{array}{l}\text { 1. Describe the indications for obstetric ultrasound } \\
\text { 2. Optimize quality of fetal images } \\
\text { 3. Determine fetal lie and presentation } \\
\text { 4. Identify the fetal heads, spine, extremities, abdomen, and thorax } \\
\text { 5. Visualize anatomic structures in more than one orthogonal plane }\end{array}$ \\
\hline Ultrasound guided procedures & Emergency medicine & $\begin{array}{l}\text { 1. Describe the differences between in plane and out of plane needle guid- } \\
\text { ance } \\
\text { 2. Describe general principles of ultrasound guided procedures } \\
\text { 3. Describe the procedural steps for an ultrasound guided IV catheter place- } \\
\text { ment } \\
\text { 4. Perform in plane and out of plane needle guidance on an ultrasound } \\
\text { phantom }\end{array}$ \\
\hline
\end{tabular}

FAST focused assessment with sonography for trauma, $2 D$ two-dimensional, $I V$ intravenous

The primary challenge for institutions initiating such a curriculum is funding the required equipment and the dedicated faculty instructor time. Prior published ultrasound curricula relied on industry funding at startup, which is not a consistent or reliable resource $[1,5]$. Integration of ultrasound into UGME also requires trained faculty well-versed in indications, limitations, benefits, and risks of POCUS; protecting their effort to dedicate to ultrasound education is a challenge [2]. We were fortunate to receive a private grant to fund the initial infrastructure set up that made matching institutional funds available to expand and continue the curriculum in its current form. We attempted to address faculty costs by adding a dedicated sonographer and peer-to-peer education by senior medical students. Additional challenges for institutions initiating such a curriculum is administrative buy-in and finding time to implement this curriculum into an already stacked curriculum.

Over the past few years, the ultrasound curriculum at WFSOM has experienced tremendous growth. Our curriculum has expanded from 8 modules in 2014 to

Table 5 Infrastructural details of program development at wake forest school of medicine

\begin{tabular}{|c|c|}
\hline Machines & $\begin{array}{l}\text { Initial grant funding } 4 \text { cart-based machines, each with a phased array, curvilinear and linear probe } \\
\text { One owned by the institution machine on permanent loan from the manufacturer } \\
\text { The success of the curriculum allowed additional machine purchases possible, to a total of } 9 \text { cart-based machines, each } \\
\text { with a 3-probe setup }\end{array}$ \\
\hline Physical space requirements & $\begin{array}{l}\text { A room large enough for } 1 \text { to } 3 \text { instructors to supervise } 5-6 \text { groups of students } \\
\text { Stretchers or exam tables are needed so that students or standardized models can lie recumbent for exams } \\
\text { The lab sessions initially were held in an available large meeting room in the medical school building. In } 2017 \text { we moved } \\
\text { to a new building and held ultrasound laboratory sessions in a large multipurpose room }\end{array}$ \\
\hline Audiovisual & $\begin{array}{l}\text { We have found it is also very helpful to have large secondary displays for group members to observe that can be reposi- } \\
\text { tioned so that student models can also see the image } \\
\text { At curriculum launch, we purchased gurneys for use during ultrasound lab sessions and two large LCD displays on port- } \\
\text { able mounts } \\
2017 \text { converted to with } 5 \text { mounted displays as well as our exiting mobile displays }\end{array}$ \\
\hline Personnel requirements & Faculty/sonographer hours per session 4-16 h (yearly estimate) \\
\hline
\end{tabular}


This assignment confirms that you are aware of the course policies and procedures - please select Yes or No for the following questions.

\section{Question 1}

I understand that my classmates and I will be serving as our own ultrasound models for this course.

Group of answer choices

cos

Yes

r

No

\section{Question 2}

I understand that I do not need to serve as an ultrasound model. If I do not wish to serve as an ultrasound model I can inform the course director or any Medical Education staff at any time. Group of answer choices

co

Yes

(c)

No

\section{Question 3}

Interactions in the Ultrasound lab will serve as a model of appropriate professional interactions. It is important to maintain a superior educational environment. I understand that degrading language, sexist comments, and other inappropriate behavior are absolutely unacceptable. Group of answer choices c

Yes

$r$

No

\section{Question 4}

Please review the following on Abnormal Findings:

\section{POLICY ON ABNORMAL OR CONCERNING FINDINGS WHEN SCANNING} STUDENTS

It is standard practice for students to serve ultrasound models for their classmates when performing large group ultrasound instruction. It is certain that at some point an abnormal ultrasound finding will be identified that may need further medical investigation. The potential for abnormal findings is not unique to ultrasound instruction and occurs whenever students perform assessments on each other (e.g. physical exam skills practice). To manage this risk we act within the following procedures and practices:

- No student will be required to act as an ultrasound model. Students may opt-out by discussing their participation as a model with the ultrasound course director.

- Students will electronically review a copy of our "Abnormal Findings" policy to confirm their knowledge of the policy. Documentation of this review will occur via Canvas.

- If abnormal findings are identified and there is concern that they would require additional medical intervention students will be referred to student health. They will be provided with a note from the Course Director describing the findings and concerns.

Please select "Yes" if you understand the above policy.

Group of answer choices

c

Yes

$c$

No

Question 5

I understand that ultrasound examinations and machine use may only happen under direct supervision from course faculty.

Group of answer choices

Yes

Y

No

Fig. 3 Wake Forest School of Medicine Student Model Policy and Policy for Management of Incidental Findings 
16 modules in 2020 with an additional ultrasound elective equaling 100 contact hours (Table 1). An active ultrasound interest group initiated by students collaborates with our faculty to develop extracurricular lab sessions on topics of interest that sometimes address ongoing innovation in subspecialty ultrasound clinical application or technology [11]. An ultrasound certificate program was introduced in 2019 to encourage clinical and research activities in ultrasound. Students choose a precepted ultrasound related activity ranging from a research project with a faculty mentor to a defined number of sessions serving as facilitators for pre-clinical medical students. Ultrasound interest group activities also contribute to certificate requirements.

The ultrasound curriculum at WFSOM shares prominent themes and characteristics with other ultrasound curricula across different institutions yet offers its own unique opportunities. Our curriculum is integrated across all four years of UGME, is structured to complement organ system-based blocks, and is formatted to present information in a multimodal fashion through a combination of lectures and handson lab sessions. Despite emphasis on anatomy, physiology and clinical concepts, the degree of exposures lends itself to significant knowledge in ultrasound image acquisition and interpretation. At WFSOM, administrative buy-in was relatively simple. There was an identified priority to provide our medical students with additional learning experiences in the areas of anatomy and physiology as well as important clinical experiences to reinforce learning. We fashioned dedicated time for ultrasound by leveraging co-existing content on the UGME academic calendar. Formatting lectures as online on-demand with a "flipped classroom" model also helped to keep the footprint within the school day as small as possible. One of our more distinctive features, the curriculum offers opportunities for specialty-specific ultrasound training during certain clerkship rotations integrated into teaching bedside examinations, the POCUS elective offered to fourth-year students, and the option to participate in the ultrasound certificate program.

\section{Conclusion}

Ultrasound integration can be a useful assistive educational method in undergraduate medical education but limited by resource intensive set up and high variability of program integration into UGME curricula. Common standards, milestones, and standardized competencybased assessments would be helpful in more application that is widespread.

\section{Appendix}

See Table 6.

Table 6 Ultrasound Curricula in Medical Education Survey

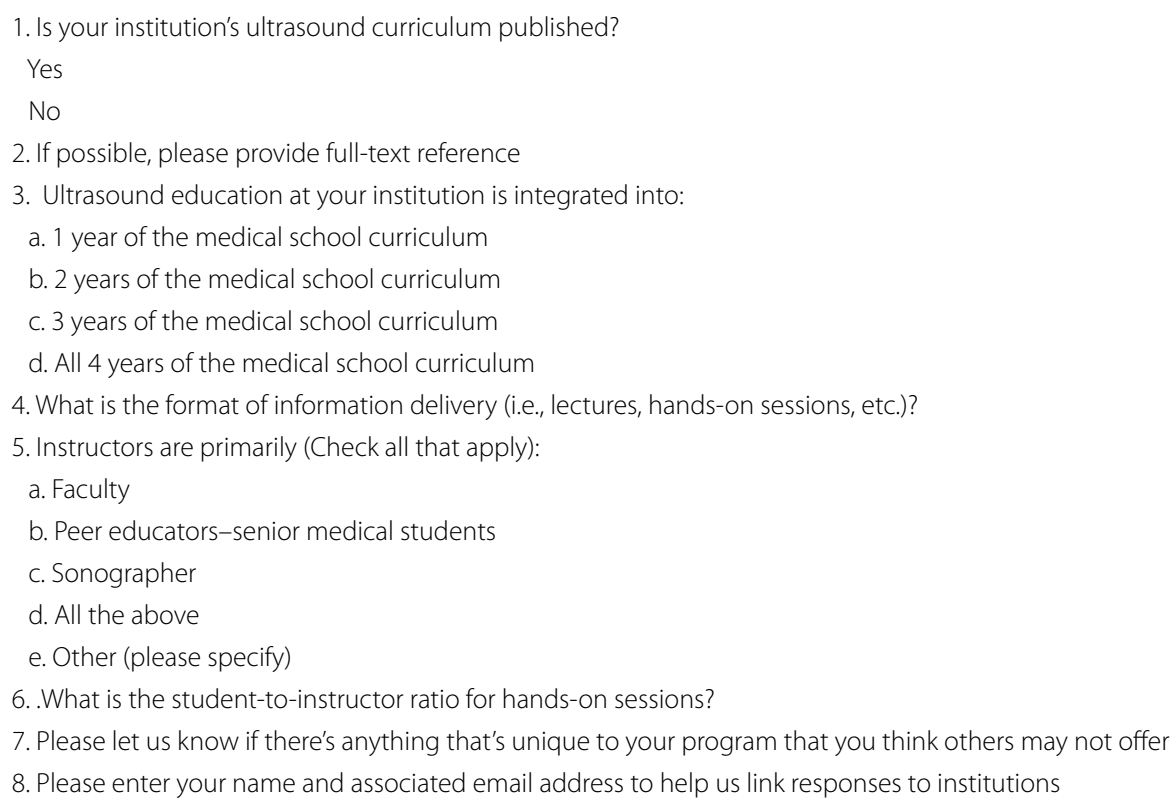




\section{Abbreviations}

ACGME: Accreditation Council for Graduate Medical Education; COMLEX-USA: Comprehensive Osteopathic Medical Licensing Examination of the United States; EPA: Entrustable professional activities; LCME: The Liaison Committee on Medical Education; MD: Doctor of Medicine; OB/GYN: Obstetrics and gynecology; POCUS: Point-of-care ultrasound; PRISMA: Preferred Reporting Items for Systematic Reviews and Meta-Analyses; UGME: Undergraduate medical education; USC-G: University of South Carolina School of Medicine-Greenville; US: United States; WFSOM: Wake Forest School of Medicine.

\section{Acknowledgements}

We have no acknowledgements to disclose.

\section{Authors' contributions}

CG is the director of the medical school ultrasound curriculum at Wake Forest School of Medicine and was involved in all aspects of the research from conception of the project to interpretation of data to development of the manuscript. AS is the co-director of the medical school ultrasound curriculum at Wake Forest School of Medicine and was involved in all aspects of the research from conception of the project to interpretation of data to development of the manuscript. JZ oversaw 4th year elective and was responsible for gathering data to be used in this manuscript. Additionally, JZ contributed to drafting of the work and its revision. JN oversaw the OB/GYN specialty and has substantively revised the manuscript. JJ is the Director of Healthcare Education and Innovation and helped gather curriculum data for Wake Forest School of Medicine. Additionally, JJ drafted the work and was involved in its revision. $\mathrm{LL}$ is the clinical research coordinator who made substantial contributions to the acquisition, analysis, and interpretation of data. Additionally, $L J$ has made extensive contributions to the drafting of the work, its revision, and its submission. JGV was the graduate student working under AS who aided in the conception of the work and has substantively drafted and revised the work. MO made substantial contributions to the design of the work; the acquisition, analysis, and interpretation of data; and has extensively revised all versions of the manuscript. All authors have read and approved the final manuscript.

\section{Funding}

The authors have no funding to disclose.

\section{Availability of data and materials}

Data sharing is not applicable to this article as no datasets were generated or analyzed during the current study.

\section{Declarations}

Ethics approval and consent to participate

Not applicable.

\section{Consent for publication}

Not applicable.

\section{Competing interests}

The authors declare that they have no competing interests.

\section{Author details}

${ }^{1}$ Department of Emergency Medicine, Medical Center, Wake Forest School of Medicine, 1 Winston-Salem, Boulevard, NC 27157, USA. ${ }^{2}$ Department of Neurology, Medical Center, Wake Forest School of Medicine, 1 Winston-Salem, Boulevard, NC 27157, USA. ${ }^{3}$ Department of Obstetrics and Gynecology, Wake Forest School of Medicine, Medical Center, 1 Winston-Salem, Boulevard, NC 27157, USA. ${ }^{4}$ Department of Medical Education, Wake Forest School of Medicine, Medical Center , 1 Winston-Salem, Boulevard, NC 27157, USA.

Received: 10 September 2020 Accepted: 30 January 2021 Published online: 19 April 2021

\section{References:}

1. Hoppmann RA, Rao W, Bell F et al (2015) The evolution of an integrated ultrasound curriculum (iUSC) for medical students: 9-year experience. Crit Ultrasound J 7(1):18-18

2. Tarique U, Tang B, Singh M, Kulasegaram KM, Ailon J (2018) Ultrasound curricula in undergraduate medical education: a scoping review. J Ultrasound Med 37(1):69-82

3. Tricco AC, Lillie E, Zarin W et al (2018) PRISMA extension for scoping reviews (PRISMA-SCR): checklist and explanation. Ann Intern Med 169(7):467-473

4. Kern DE, Thomas PA, Hughes MT (eds) (2009) Curriculum development for medical education: six-step approach, 2nd edn. Johns Hopkins University Press, Baltimore (MD)

5. Hoppmann RA, Rao W, Poston MB et al (2011) An integrated ultrasound curriculum (iUSC) for medical students: 4-year experience. Crit Ultrasound J 3(1):1-12

6. Shokoohi H, Boniface K, Kaviany P, Armstrong P, Calabrese K, Pourmand A (2016) An experiential learning model facilitates learning of bedside ultrasound by preclinical medical students. J Surg Educ 73(2):208-214

7. Akoma UN, Shumard KM, Street L, Brost BC, Nitsche JF (2015) Impact of an inexpensive anatomy-based fetal pig simulator on obstetric ultrasound training. J Ultrasound Med 34(10):1793-1799

8. Bahner DP, Royall NA (2013) Advanced ultrasound training for fourth-year medical students: a novel training program at The Ohio State University College of Medicine. Acad Med 88(2):206-213

9. Hughes DR, Kube E, Gable BD, Madore FE, Bahner DP (2012) The sonographic digital portfolio: a longitudinal ultrasound image tracking program. Crit Ultrasound J 4(1):15

10. Davis JJ, Wessner CE, Potts J, Au AK, Pohl CA, Fields JM (2018) Ultrasonography in Undergraduate Medical Education: A Systematic Review. J Ultrasound Med 37(11):2667-2679. https://doi.org/10.1002/jum.14628

11. Chiem AT, Soucy Z, Dinh VA et al (2016) Integration of ultrasound in undergraduate medical education at the California medical schools. J Ultrasound Med 35(2):221-233

12. Bahner DP, Adkins EJ, Hughes D, Barrie M, Boulger CT, Royall NA (2013) Integrated medical school ultrasound: development of an ultrasound vertical curriculum. Crit Ultrasound J 5(1):6

13. Rao S, van Holsbeeck L, Musial JL et al (2008) A pilot study of comprehensive ultrasound education at the Wayne State University School of Medicine: a pioneer year review. J Ultrasound Med 27(5):745-749

14. Afonso N, Amponsah D, Yang J et al (2010) Adding new tools to the black bag-introduction of ultrasound into the physical diagnosis course. J Gen Intern Med 25(11):1248-1252

15. Rempell JS, Saldana F, DiSalvo D et al (2016) Pilot point-of-care ultrasound curriculum at Harvard Medical School: early experience. West J Emerg Med 17(6):734-740

16. Knobe M, Munker R, Sellei RM et al (2010) Peer teaching: a randomised controlled trial using student-teachers to teach musculoskeletal ultrasound. Med Educ 44(2):148-155

17. Celebi N, Griewatz J, Malek NP et al (2019) Development and implementation of a comprehensive ultrasound curriculum for undergraduate medical students - a feasibility study. BMC Med Educ 19(1):170

18. Shapiro RS, Ko PK, Jacobson S (2002) A pilot project to study the use of ultrasonography for teaching physical examination to medical students. Comput Biol Med 32(6):403-409

19. Amini R, Stolz LA, Hernandez NC et al (2016) Sonography and hypotension: a change to critical problem solving in undergraduate medical education. Adv Med Educ Pract 7:7-13

20. Stokke TM, Ruddox V, Sarvari SI, Otterstad JE, Aune E, Edvardsen T (2014) Brief group training of medical students in focused cardiac ultrasound may improve diagnostic accuracy of physical examination. J Am Soc Echocardiogr 27(11):1238-1246

21. Zawadka M, Graczynska A, Janiszewska A et al (2019) Lessons learned from a study of the integration of a point-of-care ultrasound course into the undergraduate medical school curriculum. Med Sci Monit 25:4104-4109 
22. Bahner DP, Goldman E, Way D, Royall NA, Liu YT (2014) The state of ultrasound education in U.S. medical schools: results of a national survey. Acad Med 89(12):1681-1686

23. Medicine AloUi. Ultrasound in Medical Education Portal http://meded. aium.org/medical-schools. Accessed March 19, 2020

24. Minardi J, Ressetar H, Foreman T et al (2019) Longitudinal ultrasound curriculum incorporation at West Virginia University School of Medicine: a description and graduating students' perceptions. J Ultrasound Med 38(1):63-72

25. Baltarowich OH, Di Salvo DN, Scoutt LM et al (2014) National ultrasound curriculum for medical students. Ultrasound Q 30(1):13-19

26. Recommended Curriculum Guidelines for Family Medicine ResidentsPoint of Care Ultrasound. https://www.aafp.org/dam/AAFP/documents/ medical_education_residency/program_directors/Reprint290D_POCUS. pdf. Published 2020. Accessed March 19, 2020.

27. National Competence Based Catalogue of Learning Objectives for Undergraduate Medical Education (NKLM). http://www.nklm.de/files/nklm_ final 2015-07-03.pdf. Published 2015. Accessed March 19, 2020.

28. Hendriksz T, Markman Z, Pera A (2018) An education in osteopathic ultrasonography (AEIOU) program: one institution's approach to advancing an ultrasonography curriculum. J Am Osteopath Assoc 118(11):746-752

29. Fox JC, Schlang JR, Maldonado G, Lotfipour S, Clayman RV (2014) Proactive medicine: the "UCl 30," an ultrasound-based clinical initiative from the University of California. Irvine Acad Med 89(7):984-989

30. Wilson SP, Mefford JM, Lahham S et al (2017) Implementation of a 4-Year point-of-care ultrasound curriculum in a liaison committee on medical education-accredited US medical school. J Ultrasound Med 36(2):321-325
31. Nelson BP, Hojsak J, Dei Rossi E, Karani R, Narula J (2017) Seeing is believing: evaluating a point-of-care ultrasound curriculum for 1st-year medical students. Teach Learn Med 29(1):85-92

32. Moscova M, Bryce DA, Sindhusake D, Young N (2015) Integration of medical imaging including ultrasound into a new clinical anatomy curriculum. Anat Sci Educ 8(3):205-220

33. Kondrashova T, Lockwood MD (2015) Innovative approach to teaching osteopathic manipulative medicine: the integration of ultrasonography. J Am Osteopath Assoc 115(4):212-220

34. Kondrashova T, Kondrashov P (2018) Integration of ultrasonography into the undergraduate medical curriculum: seven years of experience. Mo Med 115(1):38-43

35. Thomas PA, Kern DE, Hughes MT, Chen BY (2015) Curriculum development for medical education: a six-step approach, 3rd edn. Johns Hopkins University Press, Baltimore, Maryland

36. Russ BA, Evans D, Morrad D, Champney C, Woodworth AM, Thaut L, Thiessen M (2017) Integrating point-of-care ultrasonography into the osteopathic medical school curriculum. J Am Osteopath Assoc 117(7):451-456. https://doi.org/10.7556/jaoa.2017.091

37. Lewis MR, Howley L, White P, Colcord C, Allen BK (2018) Development and evaluation of a longitudinal integrated ultrasound curriculum for third yearmedical students. J Reg Med Campuses. https://doi.org/10. 24926/jrmc.v1i2.1285

\section{Publisher's Note}

Springer Nature remains neutral with regard to jurisdictional claims in published maps and institutional affiliations. 